\title{
ANÁLISE DA VULNERABILIDADE EM POPULAÇÕES TRADICIONAIS DA BAÍA DE TODOS OS SANTOS (BTS) FRENTE À PERCEPÇÃO DE RISCOS
}

\author{
Brenda Elaine Silva de Jesus'; Fábio Pedro Souza de Ferreira Bandeira ${ }^{2}$ \\ 1. Bolsista PROBIC/UEFS, Graduanda em Ciências Biológicas, Universidade Estadual de Feira de \\ Santana, email: brenda. e@hotmail.com \\ 2. Orientador, Departamento de Ciências Biológicas, Universidade Estadual de Feira de Santana, \\ email: fpbandeira@gamail.com
}

PALAVRAS-CHAVE: Problemas socioambientais; Riscos; Comunidades tradicionais e locais.

\section{INTRODUÇÃO}

A Baía de todos os Santos é o segundo maior acidente geográfico do Brasil, constituindo-se de uma reentrância costeira na qual o mar penetra no continente, entre a cidade de Salvador e a Ilha de Itaparica. Por possuir paisagem natural e território de ocupação indígena, a BTS é o portal de entrada que abrigou posteriormente populações, vilas e cidades (CRA, 2001). Em seu entorno existem treze municípios que se integram por características culturais assemelhadas ou através do sistema hídrico e de navegação (CAROSO et al., 2011). Através das interações do meio biótico, físico e humano o projeto visa investigar a dinâmica da vida das populações tradicionais que habitam a porção insular e o entorno da Baía de Todos os Santos (BTS).

Devido os efeitos da atividade antrópica, a condição de vida e de trabalho assim como o ambiente físico da BTS vêm sendo alterados drasticamente (HATJE \& ANDRADE, 2009). A medida que esses eventos ocorrem, aumenta a insegurança para as populações que percebem a gravidade e a frequência dos riscos ambientais a que estão submetidas. Nesse aspecto, o conceito de vulnerabilidade ambiental contribui para o entendimento dessas problemáticas. Este conceito está ligado ao grau de sensibilidade do ambiente a danos antrópicos e naturais que possam ocorrer, e que se relaciona também com a capacidade de resiliência e de recuperação do ambiente e das comunidades afetadas (BANDEIRA et al., 2009).

Há poucos estudos sobre a vulnerabilidade das comunidades tradicionais das Zonas Costeiras do entorno da BTS. Segundo constatado pelo tribunal de contas, no que diz respeito aos impactos ambientais resultante das mudanças climáticas, deste modo esses aspectos comprometem o futuro das comunidades tradicionais residentes da área, sendo necessária a contribuição dos governos estatais e municipais, que devem estabelecer políticas de mapeamento das vulnerabilidades para a adaptação às mudanças socioambientais nesses locais

O presente trabalho teve como objetivo geral analisar a percepção de risco e vulnerabilidade socioambiental de populações tradicionais e locais no entorno da Baía de Todos os Santos, com ênfase nos municípios Madre de Deus, Candeias e Salinadas Margaridas.

\section{METODOLOGIA}

O local de estudo foram as cidades de Madre de Deus - localizada em uma das Ilhas da Baía de Todos os Santos (BTS), que no último Censo tinha uma população de 17.376 habitantes e sua economia local tem como destaque a pesca artesanal, turismo e os empreendimentos industriais; Candeias que tinha cerca de 83.158 habitantes no último Censo e Salinas da Margarida, no último senso tinha uma população de 13.456 habitantes, em 2014 tinha um PIB per capita de R $\$ 9646.39$ (IBGE, 2017). Todos esses municípios da BTS sofrem 
diversos danos socioambientais, devido aos empreendimentos industriais ativos nos seus territórios.

Primeiramente, foi realizada pesquisa bibliográficas com o intuito de levantar o que existia na literatura sobre as áreas pesquisadas (Madre de Deus, Salinas e Candeias). Logo após a revisão de literatura, uma base de dados secundários gerada a partir de entrevistas realizadas em um estudo etnográfico (MARCUS. 1991, 2001) pelo projeto guarda-chuva foi utilizada como fonte de dados. As entrevistas foram sistematizadas de acordo com as categorias analíticas definidas no estudo e na análise de conteúdo (BARDIN, 2009) e a partir disso, os dados foram graficados com o uso do programa Excel, como também analisados a partir da técnica estatística multivariada (Análise de Cluster), com o programa PAST (Versão 3.16, 2001), para análise do padrão de respostas existentes entre entrevistados. No total foram analisadas 47 entrevistas, sendo 29 de Madre de Deus, 6 de Salinas e 12 de Candeias, com ocupações variando desde pescador, Pai de Santo até servidor público. Em relação ao gênero foram 24 mulheres e 23 homens, com idades variando desde 21 a 82 anos.

\section{RESULTADOS E DISCUSSÃO}

Foram identificados 23 fatores de riscos percebidos pelos entrevistados e os mais citados foram em geral, considerando todos foram: Poluição da água (PolAg), Violência associada ao tráfico de drogas (ViTr), Poluição do ar (PolAr), Ausência de saneamento Básico (FaSb), Sistema de saúde deficitário (SiSad), Poluição Sonora urbana (PolSo). Estes riscos estão relacionados à atividade industrial e petroquímica, como também ao fato de Madre de Deus e Candeias fazerem parte da Região Metropolitana de Salvador, com alta densidade populacional e inúmeros problemas urbanos.

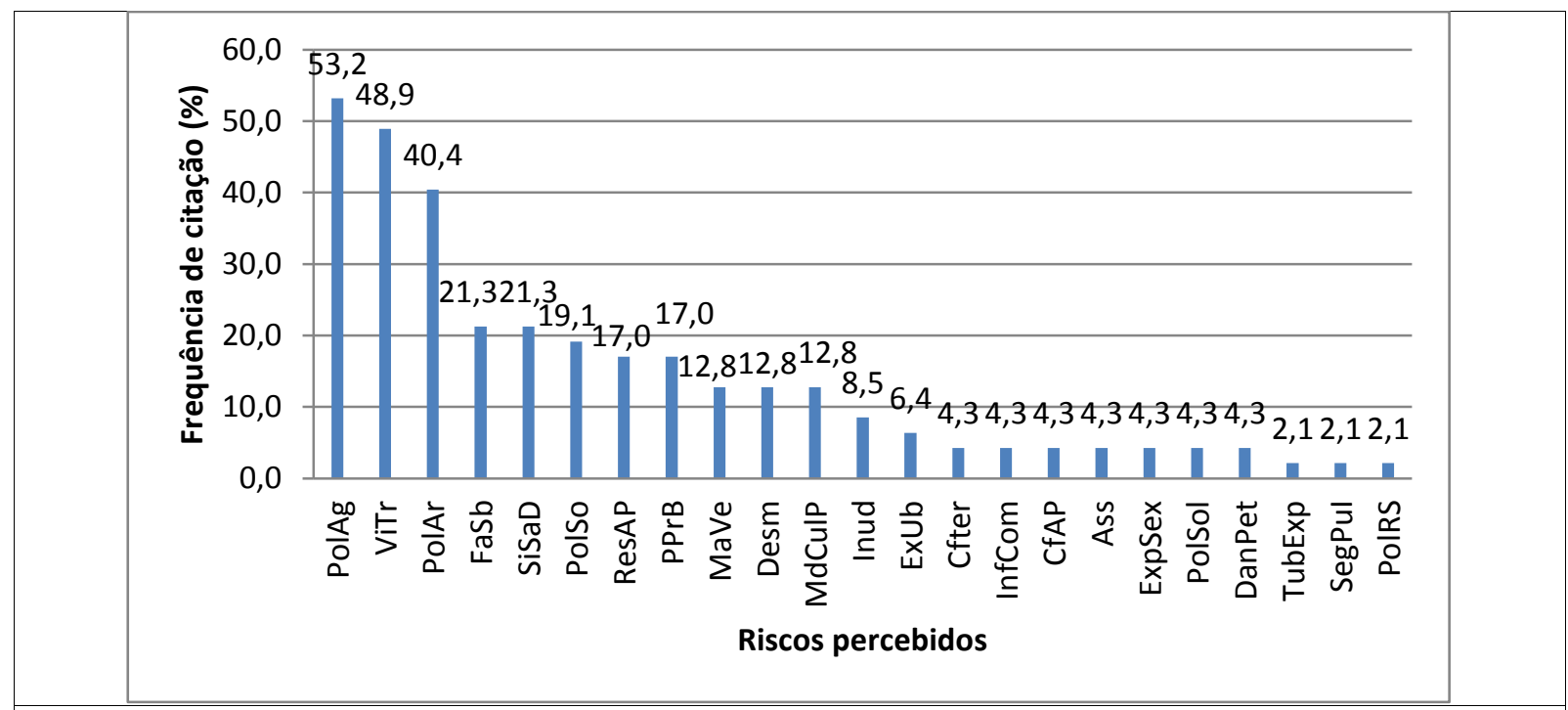

Figura 1 - Frequência de citação geral das categorias de risco percebidas por todos os entrevistados $(n=55)$ das localidades nos municípios de Candeias, Madre de Deus e Salinas das Margaridas. 


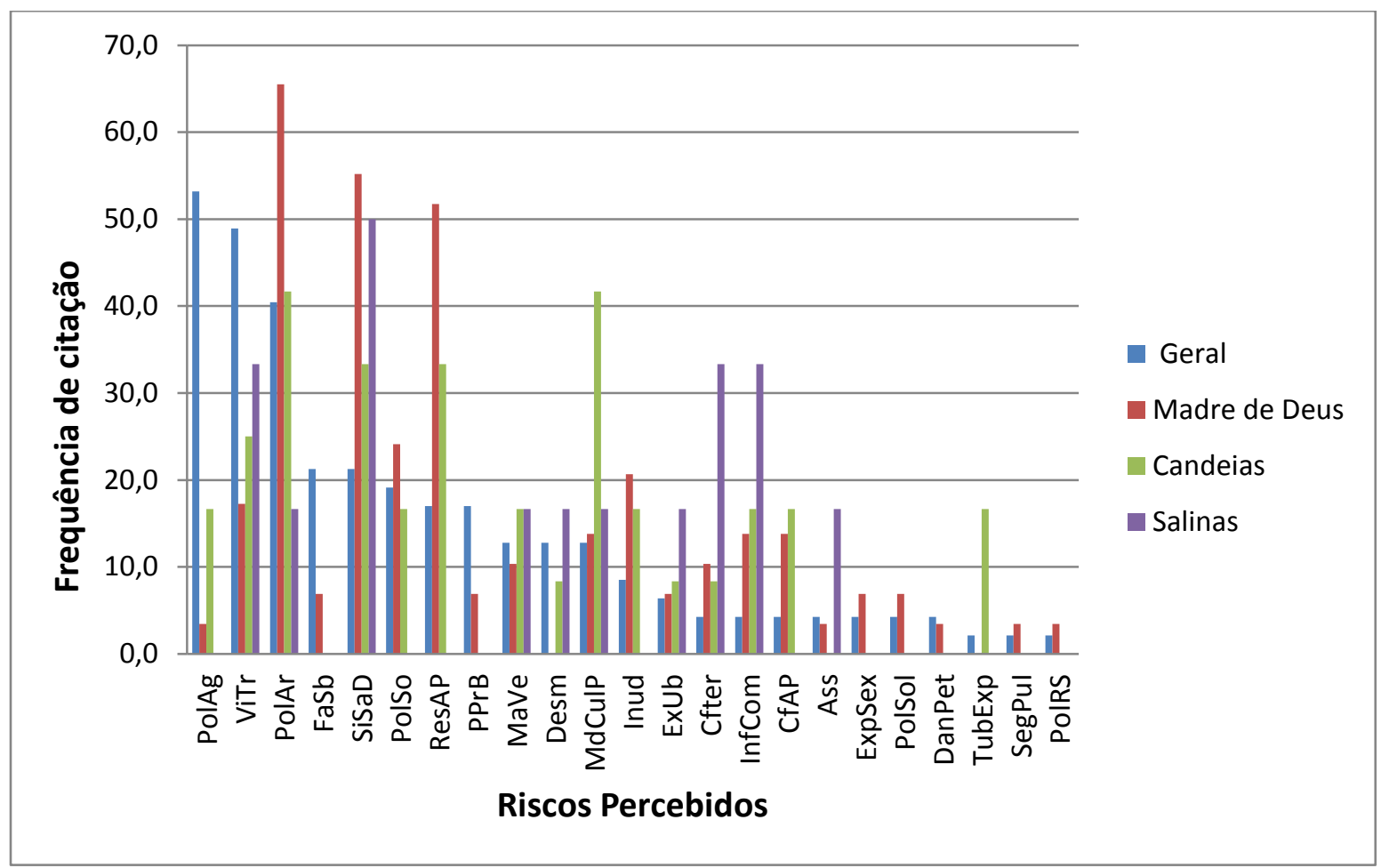

Existe um padrão de citação dos riscos, quase todos são citados pelas três comunidades, havendo uma diferença de magnitude na citação de alguns deles, a saber: Poluiçaõ do ar (PolAr), restrição das áreas pesqueiras pelas atividades industriais (ResAP) e Sistema de saúde deficitário ( $\mathrm{SiSaD}$ ) com uma maior frequência de citação em Madre de Deus, devido a presença de indústrias petroquímicas que resultam na restrição de áreas pesqueiras e na poluição do ar através da eliminação de resíduos de produção na atmosfera. Os riscos Poluição da água (PolAg), Mudança cultural na pesca (MdCulP) e Risco de explosão de instalações industriais (TubExp) foram mais citados em Candeias devido à proximidade com o Porto de Aratu e de empreendimentos industriais que são os agentes poluidores que mais contribuem para a degradação ambiental. Em Salinas os riscos mais citados foram a Falta de infraestrutura para comercialização do pescado (InfCom) e Expansão urbana em áreas de manguezal (ExUb), o primeiro está relacionado a falta de apoio para os pescadores artesanais comercializarem seu pescado, espaço ocupado pelos atravessadores, e o segundo é referente ao crescimento populacional, que pressiona o desmatamento dos manguezais para construção de casas, o que revela a forte injustiça ambiental na região, que acomete sobretudo as camadas de menor renda da população da RMS.

\section{CONCLUSÃO}

A poluição da água, a violência associada ao tráfico de drogas, a poluição do ar, a falta de saneamento Básico, e o sistema de saúde deficitário bem como a poluição sonora urbana são os riscos mais percebidos nas localidades estudadas dos municípios de Madre de Deus, Candeias e Salinas das Margaridas. Isso se deve, em parte, ao fato de que essas localidades compartilham a mesma percepção, por estarem vulneráveis aos mesmos empreendimentos industriais e ao crescimento urbano desordenado, como são o caso de Candeias e Madre de Deus. Levando em consideração a percepção de homens e mulheres não houveram discrepâncias significativas na percepção de riscos apesar de algumas categorias terem sido citadas particularmente por ambos gêneros. 
As alterações ambientais causadas pela poluição, que está entre os riscos mais citados, afetam diretamente os pescadores e marisqueiras, que dependem do ambiente natural como fonte de recurso para a subsistência familiar. Sendo assim, que as informações obtidas nesse estudo são de extrema importância para implantação de monitoramento ambiental participativo nas comunidades, e uma maior atuação junto ao poder público para controlar os impactos ambientais que mais afligem as diversas localidades da Baía de Todos os Santos.

\section{REFERÊNCIAS}

BANDEIRA,F.P.;LOBÃO, J.S.B.; JACINTHO, B. MODERCÍN， I.; SILVA， L.M.da.; RIGUEIRA, D. PIOVESAN, J.;BAQUEIRO, C.;MALAFAIA,P.;NASCIMENTO,C. 2009. Estudo Etnoecológico sobre a Percepção das Populações Ribeirinhas dos Riscos e Impactos Ambientais na Baía de Todos-os-Santos. Ed. IMA/Egba. Salvador. 138 p. no prelo.

BARDIN, L. Análise de Conteúdo. Lisboa, Portugal; Edições 70, LDA, 2009

CRA. Avaliação das áreas costeiras superficiais, BTS Praias de Salvador. Salvador/BA, março/ 2001.

CAROSO, Carlos; TAVARES, Fátima; PEREIRA, Cláudio Luiz. Baía de Todos os Santos: aspectos humanos. EDUFBA, 2011.

HATJE, V.; ANDRADE, J. B. Baía de Todos os Santos: Aspectos oceanográficos. Salvador: EDUFBA, 2009. 306p.

IBGE. Disponível em: http://biblioteca.ibge.gov.br/visualizacao/dtbs/bahia/madrededeus.pdf. Acesso em: 4 Ago. 2017. 